\title{
REVIEW
}

\section{Resuscitation training of paediatricians}

\section{F Jewkes, B Phillips}

Intensive, didactic courses teaching resuscitation training are currently not only very popular, but are also required curricula content for certain aspects of medical training. There are a number of such courses available in the field of paediatrics, each with a different emphasis and target audience. They are not inexpensive, as they utilise large amounts of training equipment and have a high instructor to student ratio. This review will examine the course structures, instructor training, the need for such courses, and effect they may have on patient outcome.

See end of article for authors' affiliations

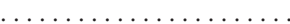

Correspondence to: Dr F Jewkes, Avon Valley Practice, Fairfield, Upavon, Wilts SN9 6DZ, UK; f.jewkes@btinternet.com

Accepted 28 October 2002
C hildren have the right to expect the same standard of care as that afforded to adults, suitably adapted to their particular requirements. With the advent of evidence based medicine, it is expected that the junior doctor in paediatrics is equipped not only to attend to the basic initial management of a very sick child, but also to address all aspects of immediate care to preset standards in a logical, sequential, and timely fashion. It is therefore important that the doctor has been taught the knowledge and skills required to face the task clearly, concisely, and in a manner to allow easy recall. In the resuscitation room, delays of even seconds may affect the outcome adversely. Simple guidelines (such as those for basic and advanced paediatric life support) have therefore been created by experts, based on best available evidence, to allow rapid decision making at a time of crisis. ${ }^{1-5}$

\section{IS THERE A NEED FOR TRAINING?}

Repeated studies of paediatric junior staff in the UK and in other Western countries have shown both a lack of knowledge and a poor ability to carry out basic lifesaving skills. ${ }^{6-9}$ In the UK, Buss et al surveyed 88 junior paediatricians in 1992 and asked a variety of questions about basic resuscitation. Knowledge was poor-only $9 \%$ had had formal training in emergency paediatrics and $94 \%$ expressed a desire for further training. ${ }^{6}$ The situation remained poor in 1996, when 57 middle grade doctors were questioned about cardiac arrest protocols and only $26 \%$ provided answers compatible with European Resuscitation Council (ERC) guidelines. Thirty per cent had received in house training in emergency paediatrics, but only 9\% were trained in Advanced Paediatric Life Support (APLS). ${ }^{7}$ More recently in the USA, where PALS training is compulsory at a junior level of training in paediatrics, senior residents still lacked adequate performance in basic resuscitation skills, although their theoretical knowledge and confidence levels were good. ${ }^{8}$ Currently, in addition to the advice of the Royal College of Paediatrics and Child Health that paediatricians should undertake an APLS course, other documents concerned with maintenance of quality care, such as the National Confidential Enquiry into Perioperative Deaths, also recommend that staff working in centres that receive injured children should be familiar with APLS guidelines. ${ }^{10}$

\section{TEACHING THE NECESSARY SKILLS AND KNOWLEDGE}

These intensive, short courses in resuscitation were pioneered in the United States, the first courses being for adult care. Other courses followed, including the Pediatric Advanced Life Support Course (PALS) in 1988. PALS has been running in the UK in its original American form since 1992. The APLS course was developed in the UK, and was piloted in 1992. Over the past 10 years other, similar resuscitation courses have sprung up, of which those relevant to paediatrics are summarised in table 1 .

\section{GENERAL COURSE OVERVIEW}

All the courses have a similar structure and present clinical material in a systematic way known as "ABC". This approach dictates that the pathology most likely to threaten the patient's life is examined and treated first. An airway problem, (A), will kill the patient before a breathing problem and will therefore be addressed immediately. Breathing (B) requires more urgent attention than a circulatory problem (C). D represents disability (neurology) which, in turn, is less urgent than C. E (exposure of the patient) is undertaken when A, B, C, and D have been stabilised. While this is logical, it is contrary to the way in which medicine is traditionally taught, where the history and full examination are completed before treatment is commenced.

The course manual (often obtainable as a stand alone publication) is sent to candidates before the course begins and the candidate is expected to read and learn the material. To facilitate this and provide feedback on knowledge retention, a precourse multiple choice examination paper is completed by the candidate and brought to day one of the course, marked, and returned. The courses themselves comprise a knowledge section, presented as lectures, sometimes with the

Abbreviations: ACLS, Advanced Cardiac Life Support; ALSG, Advanced Life Support Group; APLS, Advanced Paediatric Life Support; ATLS, Advanced Trauma Life Support; ERC, European Resuscitation Council; GIC, Generic Instructors Course; NLS, Neonatal Life Support; PALS, Pediatric Advanced Life Support 
Table 1 Summary of major paediatric life support courses in the UK

\begin{tabular}{|c|c|c|c|c|c|}
\hline Course & $\begin{array}{l}\text { Organising } \\
\text { body }\end{array}$ & Subject & $\begin{array}{l}\text { Duration } \\
\text { (days) }\end{array}$ & Audience & Comment \\
\hline $\begin{array}{l}\text { Advanced Paediatric } \\
\text { Life Support (APLS) }\end{array}$ & ALSG & $\begin{array}{l}\text { BLS and ALS for children } \\
\text { Paediatric emergencies, including } \\
\text { serious illness and major trauma; some } \\
\text { neonatal life support }\end{array}$ & 3 & $\begin{array}{l}\text { Paediatricians } \\
\text { Emergency medicine } \\
\text { doctors } \\
\text { Some anaesthetists } \\
\text { Senior paediatric nurses }\end{array}$ & $\begin{array}{l}\text { Recommended for higher } \\
\text { professional training for } \\
\text { paediatrics and accident and } \\
\text { emergency in the UK }\end{array}$ \\
\hline $\begin{array}{l}\text { Neonatal Life } \\
\text { Support (NLS) }\end{array}$ & $\begin{array}{l}\text { RC (UK) } \\
\text { Northern } \\
\text { Neonatal } \\
\text { Network }\end{array}$ & Neonatal resuscitation & 1 & $\begin{array}{l}\text { Midwives } \\
\text { Paediatricians } \\
\text { GPs }\end{array}$ & \\
\hline $\begin{array}{l}\text { Paediatric Life } \\
\text { Support (PLS) }\end{array}$ & ALSG & $\begin{array}{l}\text { BLS and ALS for children } \\
\text { Recognition of paediatric emergencies }\end{array}$ & 1 & $\begin{array}{l}\text { Doctors and nurses } \\
\text { involved in paediatric care }\end{array}$ & \\
\hline $\begin{array}{l}\text { Pediatric Advanced } \\
\text { Life Support (PALS) }\end{array}$ & $\mathrm{RC}(\mathrm{UK})$ & $\begin{array}{l}\text { BLS and ALS for children } \\
\text { Recognition of paediatric emergencies } \\
\text { Some neonatal life support }\end{array}$ & 2 & $\begin{array}{l}\text { Doctors and nurses } \\
\text { involved in paediatric care }\end{array}$ & $\begin{array}{l}\text { Franchised by the American } \\
\text { Heart Association }\end{array}$ \\
\hline $\begin{array}{l}\text { Prehospital } \\
\text { Paediatric Life } \\
\text { Support (PHPLS) }\end{array}$ & ALSG & Prehospital paediatric emergency care & $2+$ & $\begin{array}{l}\text { GPs } \\
\text { Paramedics } \\
\text { Some nurses } \\
\text { Emergency medicine staff }\end{array}$ & \\
\hline
\end{tabular}

addition of workshop discussion groups, a section devoted to the teaching of specific skills which are taught in a way to promote adult learning ${ }^{11}{ }^{12}$ and scenario practice sessions. The latter involves the simulated resuscitation of a child or baby using a mannequin and suitable equipment, and requires the candidate to integrate the knowledge and skills learnt on the other portions of the course. Candidates are required to attend all the course as it is recognised that learning and practising the skills and knowledge being presented is as important as being able to pass the examination. At the end of each course, there is an examination, usually comprising a multiple choice examination paper, demonstration of key skills, and sometimes a test of the ability to complete a scenario safely.

There is a high instructor to candidate ratio (often approximately 1:2) required on all the courses. This means that despite the fact that instructors are not paid, expenses (travel and hotel) can prove costly, particularly in more remote centres.

The courses most relevant to trainee paediatricians are discussed below.

\section{APLS}

This course was developed in the UK by a group of specialists in emergency medicine, paediatrics, anaesthesia, and surgery and was piloted in 1992 under the aegis of the British Paediatric Accident and Emergency Group, a specialty group of the Royal College of Paediatrics and Child Health. Its stated remit is to "teach doctors and nurses the skills and knowledge required to treat children with life threatening illness or injury in the first hour after presentation" and its target audience is doctors and senior nurses who are likely to encounter critically ill children on a regular basis. ${ }^{13}$ A 300 page book accompanies the course, also available as a stand alone purchase, and is now into its third edition. ${ }^{14}$ The course itself has also been extensively revised, with new course materials, including a CD-ROM with instructor material and slides being available from the beginning of 2001. An interactive CD-ROM for candidates can also be purchased. This contains still pictures and video clips of signs and procedures, and also a revision and self assessment facility, both for precourse preparation and for post-course revision.

The course is divided into three days-the first day teaches life support skills, recognition of serious illness, and management of cardiac arrest; the second, paediatric medical emergencies; and on the final day the emphasis is on the management of major trauma. The prevention of cardiac arrest and early recognition of serious illness are stressed throughout the course. Lectures and case directed workshops aim to consolidate knowledge gained from the course manual. The skills required to treat seriously ill children are undertaken on the first and third day and include basic skills such as airway management, as well as more advanced skills such as venous cutdown and surgical airway.

To provide integration of skills and knowledge, scenarios are practised on each day. Basic life support and airway skills are tested during the course and, on the final day, there is a test comprising a multiple choice question paper and a scenario. A special module for nurses has been designed to ensure that the course material is relevant to their practice. Successful completion results in certification that must be reverified every four years. Two other courses have also been designed to complement APLS and promote seamless patient care-the one day Paediatric Life Support Course, for more junior staff less likely to encounter children with life threatening emergencies, and the Prehospital Paediatric Life Support Course for those attending critically ill children before arrival at hospital. APLS is required for higher professional training in paediatrics and emergency medicine. APLS is accredited, developed and administered by the Advanced Life Support Group, and has been adopted by the European Resuscitation Council and others for paediatric training. ${ }^{13}$

\section{PALS}

PALS was piloted in the USA in 1988 and came to the UK in 1992. The course is open to all health care providers, covers all aspects of resuscitation, and provides a general approach to resuscitation. The course manual, ${ }^{15}$ which can be purchased separately, is approximately 160 pages in length. Recognition of serious illness and prevention of cardiac arrest are emphasised. The course reflects an overall $\mathrm{ABC}$ approach throughout the two days rather than concentrating in depth on specific disease processes, although trauma and neonatology are discussed in both lectures and interactive stations. Lectures support the book and there are skill stations on basic life support, airway, vascular access, and defibrillation. Interactive stations are designed to promote understanding and integration of course material. There is a multiple choice, basic airway, defibrillation, and scenario exam at the end of the course. 
PALS is administered overall by the American Heart Association and in the UK by the Resuscitation Council (UK).

It is probable that PALS will eventually cease in the UK, being replaced by a new European Resuscitation Council course (see below). However it continues to be run extensively throughout the UK at the present time.

\section{NLS}

NLS is a one day course about resuscitation at birth. Designed on the same lines as the other two courses, a course manual is available ${ }^{16}$ and lectures are supported with skill stations pertinent to neonatal resuscitation. Integration takes place with scenario practice and there is a final examination on airway management as well as a multiple choice questionnaire. NLS is administered by the Resuscitation Council (UK) and is based on the successful Northern Neonatal Network course.

This course is aimed at SHOs starting in neonatology and at midwives.

\section{INSTRUCTOR TRAINING}

Education may be defined as "a planned experience that leads to a change in behaviour". ${ }^{12}$ To be effective, adult learning must have relevance and involve the learner. In addition, most adults learn best when they have set objectives, receive positive feedback, and are allowed to reflect on the overall process. Many doctors and nurses have never learned how to teach and indeed their previous exposure to learning may have been negative. Much research therefore has gone into teaching methodology for modern resuscitation courses, and the recognised principles of adult learning are reflected in the course that has been developed to train instructors.

The Resuscitation Council (UK) and the ALSG have agreed that it is only appropriate to have one (Generic) Instructors Course (GIC) for APLS, NLS, and PALS and indeed a number of other resuscitation courses. This has the advantage that if someone is invited to instruct on more than one of these courses, they do not have to repeat their instructor training, saving time and money. Students may therefore come from a variety of course backgrounds on any one GIC.

For APLS, NLS, and PALS it is required that the future instructor has attended the course as a provider (student), regardless of their background, seniority, or experience. This permits familiarity with the course content and teaching methods and allows an assessment to be made as to the suitability of an individual to be an instructor. Selection as a future instructor depends on good performance during the course, an interest in becoming an instructor, and demonstration of good teamworking skills. Credibility and an ability to accept the philosophy of this kind of teaching are additional essential elements. An assumption can therefore be made on the instructor course that the provider course material has already been assimilated, allowing the instructor course material to concentrate on educational techniques.

Professional medical educators and senior instructors from the various courses involved have jointly developed the GIC. The three day course includes instruction on lecturing, running skill stations, workshops, discussion groups, and scenarios. Future instructors are also taught how to assess candidates in an examination. Formative assessment takes place throughout the course and feedback is provided regularly to candidates, using a system whereby a designated instructor acts as a "mentor" to one or more candidates. There is no formal examination.

\section{DO THEY WORK?}

There are a number of difficulties in establishing whether patients have an improved outcome when cared for by those who have undertaken a paediatric life support course, but accumulating evidence suggests that this may be the case.
Very large patient numbers are required to show an improvement in outcome, and resuscitation events (particularly those involving only children) are relatively rare. Additional confounding factors are the heterogeneity of populations and the variation in facilities, equipment, and expertise from hospital to hospital. Other reasons for improvement in outcome such as scientific advances, are, furthermore, inevitable when accumulating data such as this which must necessarily occur over a significant time period. ${ }^{17}$

Nevertheless, attempts have been made to quantify the success of this type of teaching. Jabbour and colleagues ${ }^{18}$ in the USA examined 17 studies pertaining specifically to life support courses (Advanced Cardiac Life Support, modified APLS, Basic Cardiac Life Support, Advanced Trauma Life Support (ATLS), PALS, and the Neonatal Resuscitation Program) and detailed the difficulties in analysis. Although there was some evidence that ATLS training, which has been extensively studied, improves morbidity and mortality, 5/8 studies showed no improvement in knowledge and $8 / 9$ no improvement in skills retention. Jabbour et al conclude that studies of change in practice following course participation and well constructed patient outcome studies may be more discriminatory than skill retention and review studies. However, only three of the studies included in this analysis involved paediatric emergency care, and one (of these) was directed towards attitude to resuscitation rather than outcome. ${ }^{19}$ The second was written before any specific paediatric courses were devised and related findings to the adult Advanced Cardiac Life Support (ACLS) course..$^{20}$ The remaining study found that there was improved confidence and preparedness in office pediatricians who had undertaken either ACLS or (a US version of ) APLS. ${ }^{21}$ Another study examined PALS trained residents and provided an additional training programme in resuscitation to a study group. The group who received additional training beyond PALS fared better in terms of leadership and technical and assessment skills. ${ }^{22}$

In the UK, Carapiet and colleagues ${ }^{9}$ undertook a telephone based questionnaire to 94 junior doctors in 1999. Clinical scenarios were presented and the responder assessed for the ability to adhere to accepted international guidelines. The same questions were used as in the study Buss et al undertook in $1992^{6}$ to assess the need for resuscitation training. Overall, knowledge had improved over this period, and the doctors who attended APLS or PALS scored significantly better in some questions and overall obtained higher scores.

Turning to paediatric outcome in the UK, figures from the Major Trauma Outcome Study, a multicentre study examining the outcome of more than 3000 seriously traumatised patients of all ages, show that there was a $16 \%$ reduction in mortality per year for the seven years from 1989 until 1995 for patients aged 0-24 years. The improved survival rates did not differ across the age groups studied $(0-4,5-14,14-24$ years $) .{ }^{23}$ Both APLS and PALS were introduced into the UK in 1992, so it may be that these courses were among factors that improved outcome.

It would seem that, on balance, the teaching is having some impact on doctors' knowledge and confidence to treat, and therefore patient care is likely to have benefited.

\section{SKILL RETENTION AND THE FUTURE}

Skill retention depends on the frequency with which the skill is performed and the degree of complexity. In cardiopulmonary resuscitation training, there is considerable evidence that skills decay rapidly and that frequent reinforcement is necessary, ${ }^{24} 25$ and this appears to apply to skills taught on other life support courses. ${ }^{18}$ Retraining builds confidence ${ }^{26}$ and appears to improve skill and knowledge, but needs to be frequent. ${ }^{24}$

There are already significant cost implications in sending all paediatricians, even occasionally, on resuscitation courses, and 
the recertification time periods for the courses are too infrequent for optimal skill retention. To recertify more frequently would be impractical in terms of absence from work, instructors required to teach, and other resources. One alternative under consideration is an initial course, followed by a planned programme of reinforcement. The APLS interactive CD-ROM will enable students to undertake revision study and self assessment as their own needs dictate. Information technology may soon also allow more interactive resuscitation software ${ }^{27}$ to allow some form of scenario practice and thus skill and knowledge integration.

\section{OTHER COUNTRIES}

The American Heart Association's PALS course has been widely used, especially in South America. APLS has been introduced to a number of countries worldwide, including Australia, New Zealand, South Africa, and several other European countries. APLS allows minor adaptations according to the needs of the country-for example, Australia has introduced a workshop on envenomation. Variations in protocols also have been made for countries which do not have the same drug availability as the UK, but the basic principles of patient management are maintained. There is evidence from other similar courses that this type of teaching may benefit patient outcome in less developed countries. ${ }^{28}$ In conjunction with Child Advocacy International, a charity dedicated to improving hospital care and advocacy for children in the poorest countries, APLS, together with courses for maternal and newborn health, are developing a course relevant to the needs of developing nations.

\section{THE FUTURE}

The European Resuscitation Council is working to introduce a course for paediatric training. This will include basic and advanced life support for children, resuscitation at birth, and resuscitation in trauma, but not the management of life threatening illness. The course is under discussion by a multinational group chaired in Belgium and was piloted in Italy in October 2002. It is likely that if the course meets the needs of UK training requirements for resuscitation, it will replace the American Heart Association PALS course run by the Resuscitation Council (UK), but will not replace APLS.

\section{Authors' affiliations}

F Jewkes, Avon Valley Practice, Upavon, Pewsey, Wilts, UK

B Phillips, Royal Liverpool Childrens Hospital, Alder Hey, Liverpool, UK

\section{REFERENCES}

1 American Heart Association, in collaboration with the International Liaison Committee on Resuscitation (ILCOR). Part 9. Pediatric basic life support. Resuscitation 2000;46:301-41.
2 American Heart Association, in collaboration with the International Liaison Committee on Resuscitation (ILCOR). Part 10. Pediatric advanced life support. Resuscitation 2000;46:343-99.

3 American Heart Association, in collaboration with the International Liaison Committee on Resuscitation (ILCOR). Part 11. Neonatal resuscitation. Resuscitation 2000:46:401-16.

4 The Resuscitation Council (UK). Resuscitation guidelines. London: Resuscitation Council, 2000:35-51.

5 Hamilton P (Chairman). Royal College of Paediatrics and Child Health, Royal College of Obstetricians and Gynaecologists. Resuscitation of babies at birth. London: BM Publishing Group, 1997.

6 Buss PW, McCabe M, Evans RJ, et al. A survey of basic resuscitation knowledge among resident paediatricians. Arch Dis Child 1993:68:75-8.

7 Buss PW, Evans R, McCarthey G, et al. Paediatricians' knowledge of cardiac arrest guidelines. Arch Dis Child 1996;74:47-9.

8 Nadel FM, Lavelle JM, Fein JA, et al. Assessing pediatric residents' training in resuscitation: fund of knowledge, technical skills and perception of confidence. Pediatr Emerg Care 2000;16:273-6.

9 Carapiet D, Fraser J, Wade A, et al. Changes in paediatric resuscitation knowledge among doctors. Arch Dis Child 2001;84:412-14.

10 Callum KG, Gray AJG, Hoile RW, et al. Extremes of age. The 1999 report of the National Confidential Enquiry into Perioperative Deaths. London: National Enquiry into Perioperative Deaths, 1999.

11 Bullock I. Skill acquisition in resuscitation. Resuscitation 2000;45: 139-43.

12 Mackway Jones K, Walker M. Pocket guide to teaching for medical instructors. London: BM Books, 1999

13 Phillips BM, Mackway-Jones K, Jewkes F. The European Resuscitation Council's Paediatric Life Support Course "Advanced Paediatric Life Support". Resuscitation 2000;47:329-34.

14 Advanced Life Support Group. Advanced paediatric life support-the practical approach, 3rd edn. London: BMU Books, 2001.

15 Chameides LC, Hazinski MF, eds. Pediatric advanced life support. Dallas: American Heart Association, 1997.

16 Resuscitation Council. Newborn life support provider manual. London: Resuscitation Council (UK), 2001

17 Carly S, Driscoll P. Trauma education. Resuscitation 2001;48:47-56.

18 Jabbour M, Osmond MH, Klassen TP. Life support courses: are they effective? Ann Emerg Med 1996;26:690-8.

19 O'Marcaigh AS, Koenig WJ, Rosenkrans JA, et al. Cessation of unsuccessful pediatric resuscitation: how long is too long? Mayo Clinic Proc 1993;68:332-6

20 Fuchs S, Jaffe DM, Christoffel KK. Pediatric emergencies in office practices: prevalence and office preparedness. Pediatrics 1989;83:931-9.

21 Schweiz PJ, De Angelis C, Duggan AK. Preparedness of practising pediatricians to manage emergencies. Pediatrics 1991;88:223-9.

22 Nadel FM, Lavelle JM, Fein JA, et al. Teaching resuscitation to pediatric residents. The effect of an intervention. Arch Pediatr Adolesc Med 2000;154:1049-54.

23 Roberts I, Campbell F, Hollis S, et al. Reducing accident death rates in children and young adults: the contribution of hospital care. BM 1996:313:1239-41.

24 Berden HJJM, Willems FF, Hendrick JMA, et al. How frequently should basic cardiopulmonary resuscitation training be repeated to maintain adequate skills? BM 1993;306:1576-7.

25 McKenna SP, Glendon Al. Occupational first aid training: decay in cardiopulmonary resuscitation (CPR) skills. J Occup Psychol 1985;58:109-17.

26 Lester CA, Donnelly PD, Assar D. Lay CPR trainee: retraining, confidence and willingness to attempt resuscitation 4 years after training. Resuscitation 2000;45:77-82

27 Marriott C. Personal communication, Merchant Nightingale Ltd.

28 Ali J, Adam R, Butler AK, et al. Trauma outcome improves following the Advanced Trauma Life Support program in a developing country. J Trauma 1993;34:890-98. 